\title{
Segunda mitad del siglo xx en Chile: La crisis como fenómeno crítico y regenerativo de la modernidad ${ }^{* *}$
}

\author{
The second half of the $20^{\text {th }}$ century in Chile: The crisis as a critical and regenerative \\ phenomenon of modernity
}

<Resumen>

La promesa venturosa de la modernidad mantenida hasta los años 50 en Chile, fue gravemente cuestionada durante los 60 . Debates arquitectónicos que apuntaban las falencias del desarrollo sobre un medio social menesteroso exponían la crisis generalizada del sistema. La ciudad y la arquitectura se revelaron como ejemplos de la crisis.

$<$ Abstract $>$

The fortunate promise of modernity maintained until the 50 s in Chile, was seriously questioned during the 60s. Architectural debates that pointed out the flaws of the development of a needless social medium exposed the wide crisis of the system. The city and the architecture were revealed as examples of the crisis.

<PALABRAS CLAVE>

MODERNIDAD / DESARROLLISMO / URBANISMO /

ARQUITECTURA / HISTORIA

-KEYWORDS>

MODERNITY / DEVELOPMENT / URBANISM /

ARCHITECTURE / HISTORY
El influjo desarrollista de los años cincuenta en Chile fue una energía rápidamente interrumpida y cuestionada. Durante la década de los sesenta se extendió una verdadera mutación social de orden histórico y cultural que buscó por todos sus medios la modificación de la historia en curso. El juicio sobre lo realizado bajo la esperanzada época del establecimiento de la modernidad que había antecedido a este período dio paso al desencanto, la desilusión y las contundentes críticas sobre el manejo de la realidad.

Precisamente, la desmejorada realidad latinoamericana corporeizó un encendido espíritu de los tiempos. El cuestionamiento, el debate, la denuncia y la controversia se sobrepusieron a la imagen artificiosa de una modernidad posbélica incapaz de sobrellevar la magnitud de las necesidades sociales.
Por una parte, la importancia que alcanzó el debate sociológico y sus implicancias con el medio urbano y, por otra, las nuevas formas de percepción sobre la comprensión del espacio indujeron a considerar al hombre y sus vicisitudes históricas como motivo centra del debate arquitectónico. En consecuencia, los acusados defectos sobre la gestión de la ciudad y de la vivienda revelaron el ambiente de escasez que padecía un alto porcentaje de la población.

Chile no fue ajeno a ese ambiente. El desequilibrio en el desarrollo regional, la centralización política, la segregación socioeconómica, la emigración masiva a las ciudades, las ocupaciones espontáneas de los cinturones de la ciudad, etc., motivaron la transformación del debate sobre el sentido de la arquitectura.

* Pablo Fuentes Hernández es Máster en Conservación y Restauración del Patrimonio y profesor de la Escuela de Arquitectura de la Universidad del Bío-Bío.

** Investigación Universidad del Bío-Bío, DIUBB Nº74602 1/R. 


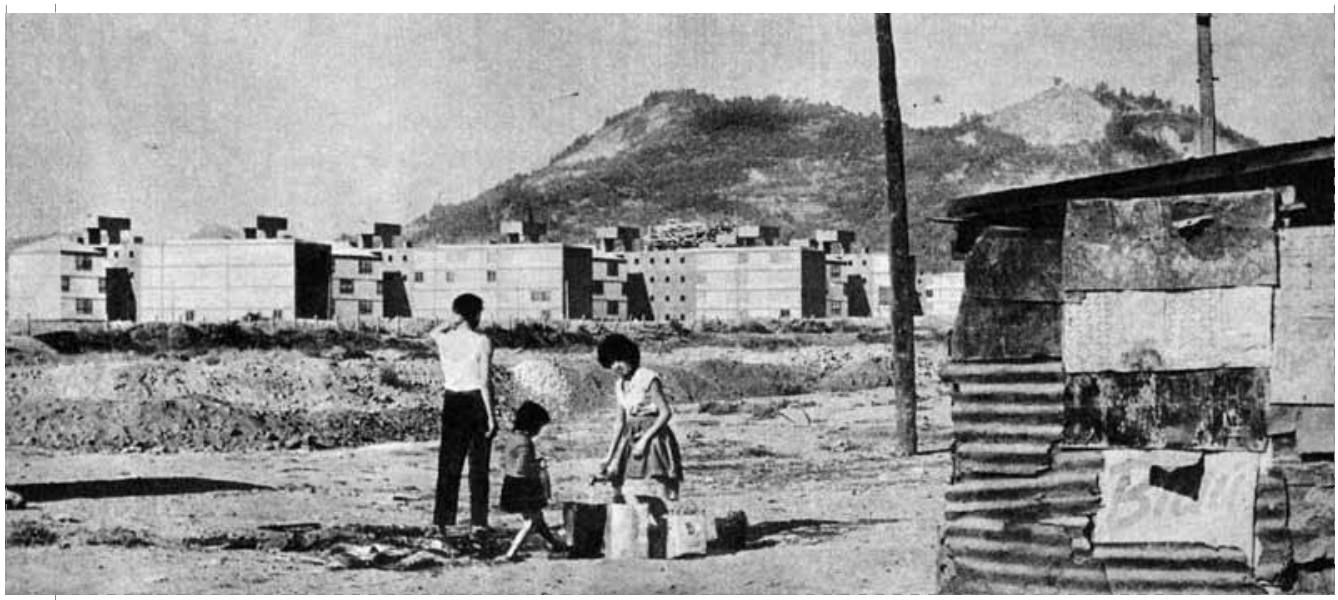

Se puede decir también que la velocidad de los cambios sobrepasó la comprensión racionalista del hecho arquitectónico, cuestión que devino a partir de este momento en significados ricos y abundantes que matizaron, unas veces complementaron y otras contradijeron al proceso racionalista.

Para el caso, se proponen dos sistemas de comprensión de esta crisis. Por una parte se desea mostrar que la ideologización de la arquitectura, supone la explicación de un marco general que articula las cuestiones políticas, sociológicas y antropológicas que ponen al hombre como centro del debate arquitectónico. En segundo lugar, se mostrará que la crisis social estaba en correspondencia directa con el urbanismo de la época y, que la crisis sobre esta disciplina es parte de un argumento disciplinario cuyo objetivo es denunciar que la sociedad chilena estaba lejos de alcanzar un nivel de bienestar asociado a su hábitat y provocar a través de ella un cambio cualitativo.

\section{La ideologización crítica de la arquitectura}

Una de las cuestiones que establece una contradicción al interior del proceso de consolidación de la modernidad arquitectónica en Chile desarrollado a partir de 1952 es que en el seno su propio transcurso se comenzó a enunciar un acelerado desgaste de sus principios. Se trató de una manifestación cuyo devenir había tenido una incorporación acelerada, comprimida y desprogramada que llegó a tensar el ambiente de la época. La incapacidad de la modernidad para resolver los conflictos de la vida cotidiana e institucional en breve plazo desencadenó una suerte de postura ideológica cuyos fundamentos se basaban en la exposición de la crisis del sistema.

En el contexto general, el espíritu de los tiempos en los sesenta estaba en directa relación con la crisis de las instituciones seculares. En ese marco el Estado, la religión, parte de las instituciones sociales y civiles fueron enjuiciadas con el propósito de abandonar su inmovilidad, muchas veces decadente o ineficaz. Francisco Aedo, por ejemplo, fijó su atención en la relación entre familia y vivienda -uno de los problemas históricos de la arquitectura- por su falta de correspondencia sociológica.

\section{«(...), la programación de la vivienda} unifamiliar supone la aceptación de la familia actual como fórmula programática invariable de vida. Le atribuimos a la familia relaciones de afecto, de jerarquía, de dependencia. Suponemos que debe descansar, debe comer y realizar expansiones en común. Suponemos que la influencia del conjunto familiar es benéfica para los jóvenes vástagos y sobre tal esquema familiar hemos edificado el esqueleto de la sociedad contemporánea.

Esta interpretación genera un programa de arquitectura muy esquemático, ya que concluye en la proposición de innumerables celdillas habitacionales que construimos desde hace milenios sin haber analizado, si en la fecha presente, satisfacen o no al tipo de relaciones que aglutina a la familia contemporánea» ${ }^{1}$. la familia, la sociedad, la universidad y gran
Entre las razones que motivaron ese desgaste se encuentra el arrollador avance científico posbélico que implicó no sólo cambios de pensamiento sino de expresión. En este sentido, las ciencias, el arte y la investigación fueron cuestiones que aparecieron con capacidad de cambiar la realidad. No obstante, a pesar del entusiasmo estimulado por el fin de la II Guerra Mundial, las limitaciones materiales de Latinoamérica imposibilitaron su incorporación al proceso desarrollista. Por esa razón, la dependencia tecnológica, científica, artística, económica y política de EE.UU., y Europa no hizo más que acentuar las distancias entre desarrollo y subdesarrollo. La presentación del progreso internacional a través de los medios de comunicación, las modas, las necesidades y el consumo colisionó con el subdesarrollo local, para entonces más próximo a la escasez, la necesidad y la privación.

En ese sentido, la sociedad avizoró rápidamente sus graves carencias y, en consecuencia, precisó de cambios inmediatos. Tal urgencia fue determinante para el cuestionamiento sobre la consolidación de la modernidad, para entonces, más bien aparente que completa. La necesidad de acciones inmediatas apareció como motivo central del discurso de la época.

\section{La arquitectura moderna, una disciplina} determinada por su energía de naturaleza cultural apareció de pronto estancada en comparación a las ciencias y al arte en Chile. El proceso de aprendizaje y apropiación de los principios de la nueva arquitectura no llegó a estimular un «decurso regular y fluido»². El fracaso de la internacionalización del Movimiento Moderno en distintos países latinoamericanos, cuyos resultados fueron tan dispares como limitados, acentuó ese declive. En lo social, las aspiraciones colectivistas de la modernidad arquitectónica entraron en franca oposición con la segregación urbana producida en Chile entre las capas bajas, medias y altas, lo que se hizo una característica notoria de la ciudad. La imitación de los recursos morfológicos de la arquitectura moderna truncó en parte un desarrollo afín. Igual cosa aconteció con las modas y las soluciones formales extendidas de forma acrítica. Por lo mismo, la falta generalizada de formulaciones originales en la práctica y en la enseñanza de la arquitectura fue otra forma de desgaste. 
«Nuestra Arquitectura padece de improvisación. La extensión de este estudio no nos ha permitido referirnos a otras circunstancias limitáticas (sic) de la labor de Arquitecto que se hacen presente fuera del taller académico. Ellas son, sin embargo, tan evidentes que han condicionado una actitud de frustración de los jóvenes frente a los problemas teóricos de la Arquitectura y frente a las disciplinas científicas que son su base, al no constatar una consecuencia lógica entre ellos y el medio objetivo del trabajo» ${ }^{3}$.

La falta de coherencia entre realidad, discurso teórico y desarrollo científico de la arquitectura moderna evidenciaron su incongruencia con el medio objetivo de trabajo. En este sentido la obra contemporánea, sea urbana o arquitectónica, fue apreciada como una forma exógena sin capacidad de generar interpretación cultural.

«Mientras en otros países americanos el pueblo siente como suyos por lo menos una parte de los edificios contemporáneos, y los señala, incluso, orgullosamente y reconoce nombre y aun las personas que crearon esas obras, en nuestro país toda obra contemporánea es sentida profundamente extraña y sólo se la acepta por la presión de los acontecimientos, como un hecho consumado» ${ }^{4}$.

En esas contexto, el nuevo entorno construido ignoró los factores cualitativos del usuario, es decir, los culturales, psicológicos y antropológicos. La incapacidad del Estado, la sociedad y los arquitectos de intervenir en el entorno físico y humano para complementar las transformaciones modernas, a diferencia de países desarrollados, era otra fuente de descrédito.

"Últimamente ha surgido en distintos países una creciente preocupación por la acción deshumanizante que el diseño moderno está produciendo a distintos niveles. Esta situación es especialmente tangible en países altamente desarrollados e industrializados, ya que estas características les dan más posibilidades que a otros de construir su entorno. Esto ha llevado a sus especialistas en Arquitectura y Urbanismo a investigar la relación entre entorno e individuo y descubrir los efectos producidos por esta relación, para así llegar a un diseño que satisfaga también las necesidades psicológicas y sociales del hombre» ${ }^{5}$.

Sin embargo, el desgaste de la modernidad tuvo una vía de escape a través de una nueva comprensión social del hecho contemporáneo. En ese marco, la arquitectura con reivindicaciones sociales pareció la fuente que respondía al desgaste. Se puede decir que la arquitectura, si bien históricamente ha respondido a determinadas cuestiones colectivas, este objetivo alcanzó en esta época el cenit de su ubicación en torno a la creación arquitectural.

Por ejemplo, F. Aedo concibió el espacio arquitectónico como el recipiente de una actividad social programada. En sus palabras la arquitectura debe «ordenar el espacio creando una sucesión de relaciones que satisfaga el funcionalismo racional de una actividad social» 6

En ese contexto la crítica al funcionalismo utilitario fue uno de lo argumentos preferidos para desarmar el discurso racionalista. La noción de utilidad, más allá del uso óptimo, comenzó a transformar su concepción. Si bien era congruente con las necesidades materiales que demandaba la situación económica nacional, esta valoración apareció exponiendo una suerte de distorsión que consistía en «olvidar que lo útil es lo que sirve para algo», es decir, como referido a una instancia superior inamovible ${ }^{7}$. La diferencia residía en que para la arquitectura no era la función la instancia superior, sino el hombre. Esa distorsión estaba en la base de la crítica a arquitecto moderno en tanto este profesional aparecía responsable de contribuir al estánda de vida de su pueblo y no de contribuir a la vida de su pueblo. Esta diferencia semántica apuntaba a la comprensión del hombre como individuo y como pueblo histórico propietario de anhelos y esperanzas cuya existencia se situaba en el "centro del ser hombre» ${ }^{8}$. 0 sea, en el caso de la arquitectura el «para qué sirve» entraba en consonancia con «qué necesidad humana le ha dado origen ${ }^{9}$. En este marco, vida y necesidades, fueron un binomio de nueva comprensión que precisó el entendimiento de una nueva responsabilidad creadora como eje del quehacer profesional del arquitecto.

Por otra parte, si el hombre vive en sociedad y ésta está determinada por los valores de la comunicación; la arquitectura, entonces, sería un lenguaje actuante. De esta forma, la arquitectura debería estar en condiciones de comunicar el sentido de las acciones a cuyo cobijamiento está destinada. Su dimensión comunicativa estaría determinada por la llegada a una comunidad cultural de dominio colectivo. Asimismo, la arquitectura está para servir y cobijar al «nosotros» mediante el control de la naturaleza.

«(...) así somos porque así vivimos, porque así actuamos para hacer del universo hosti nuestro mundo dominado, un mundo para nosotros» ${ }^{10}$.

El «nosotros», dice L. Vaisman, no sólo surge de la presencia física conjunta de los humanos, sino de su coparticipación en intenciones, valores y tareas comunes. Los medios de comunicación -como la arquitectura- cobran un papel esencial en su convivencia. El espacio arquitectónico debe responder a las condiciones físicas y psíquicas en correspondencia a los actos humanos que ha de acoger. Este es el paso en que la arquitectura encarna los valores y aspiraciones de la sociedad, expresando -comunicandoen consecuencia su sentido social. Así, la arquitectura expresa en su forma la vida social "como vida histórica concreta en un tiempo y en su lugar» ${ }^{11}$

Es en este punto donde el hombre y la historia, en su sentido político, cobra importancia. En este marco, la comprensión del hombre, ya más como ente histórico que biológico, aparece como sujeto creador y transformador de su mundo, sostenedor de su cultura, dueño de su historia.

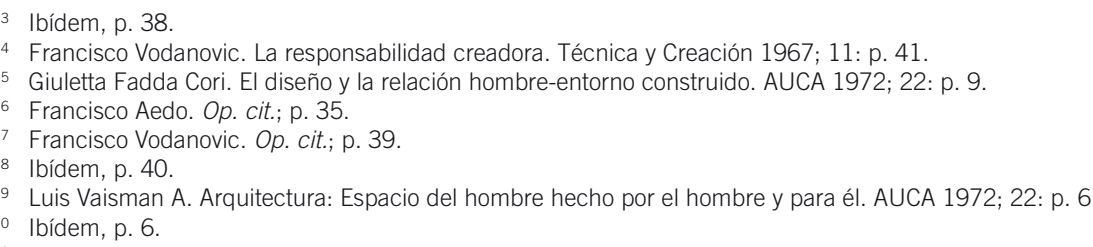


«(...) Deseamos, penetrando la viscosa bruma económico-utilitaria, comprender la vida que es, el hombre como individuo y como pueblo histórico, que posee anhelos, esperanzas o voluntad afirmativa de instancias ajenas a todo «economismo» y que son las que otorgan sentido, justamente a toda preocupación económica. Queremos situarnos en el verdadero centro del ser hombre y rehuir la posición «excéntrica» a que nos arrastra la inercia mental contemporánea» ${ }^{12}$.

\section{La ciudad en crisis}

La crisis del urbanismo en Chile tuvo al menos dos planos de debate. Por una parte, desde el punto de vista teórico, el cuestionamiento sobre los fundamentos CIAM se extendió entre los profesionales chilenos. Por otra, el deterioro evidente sobre las estructuras urbanas era la fuente más palpable del desencanto.

Una de las formas más evidentes de la crisis de la sociedad moderna fue el estado al que habían llegado las estructuras urbanas durante los años 60. Para entonces, el crecimiento demográfico había sobrepasado los límites de la ciudad tradicional. La implementación de los principios del urbanismo funcional en algunos puntos de la ciudad, propagados desde los CIAM, y las operaciones sobre la ciudad determinadas por los planes reguladores existentes a la fecha, se habían comportado como instrumentos poco eficaces. La tendencia de estos instrumentos a permanecer anquilosados en el mantenimiento de las estructuras urbanas tradicionales parecía su principal problema.

Por una parte, el descrédito sobre la estratificación de las cuatro funciones urbanas establecidas al interior de los CIAM, una doctrina de gran aceptación ideológica entre los arquitectos latinoamericanos de mediados del siglo xx, comenzó a expandirse en el medio profesional. Este debate se encuentra por primera vez en el seno del $X$ Congreso Panamericano de Arquitectos (Buenos Aires, 1960). La acusación versó de haber simplificado las actividades sociales a 4 funciones, llamadas ahora «un pegajoso slogan propagandístico» que hacía parecer a la ciudad un escenario brutalmente estructurado en unas pocas áreas ${ }^{13}$. Esta cuestión se observó como un proceso inadaptado en el paso de la teoría a la práctica. El contenido

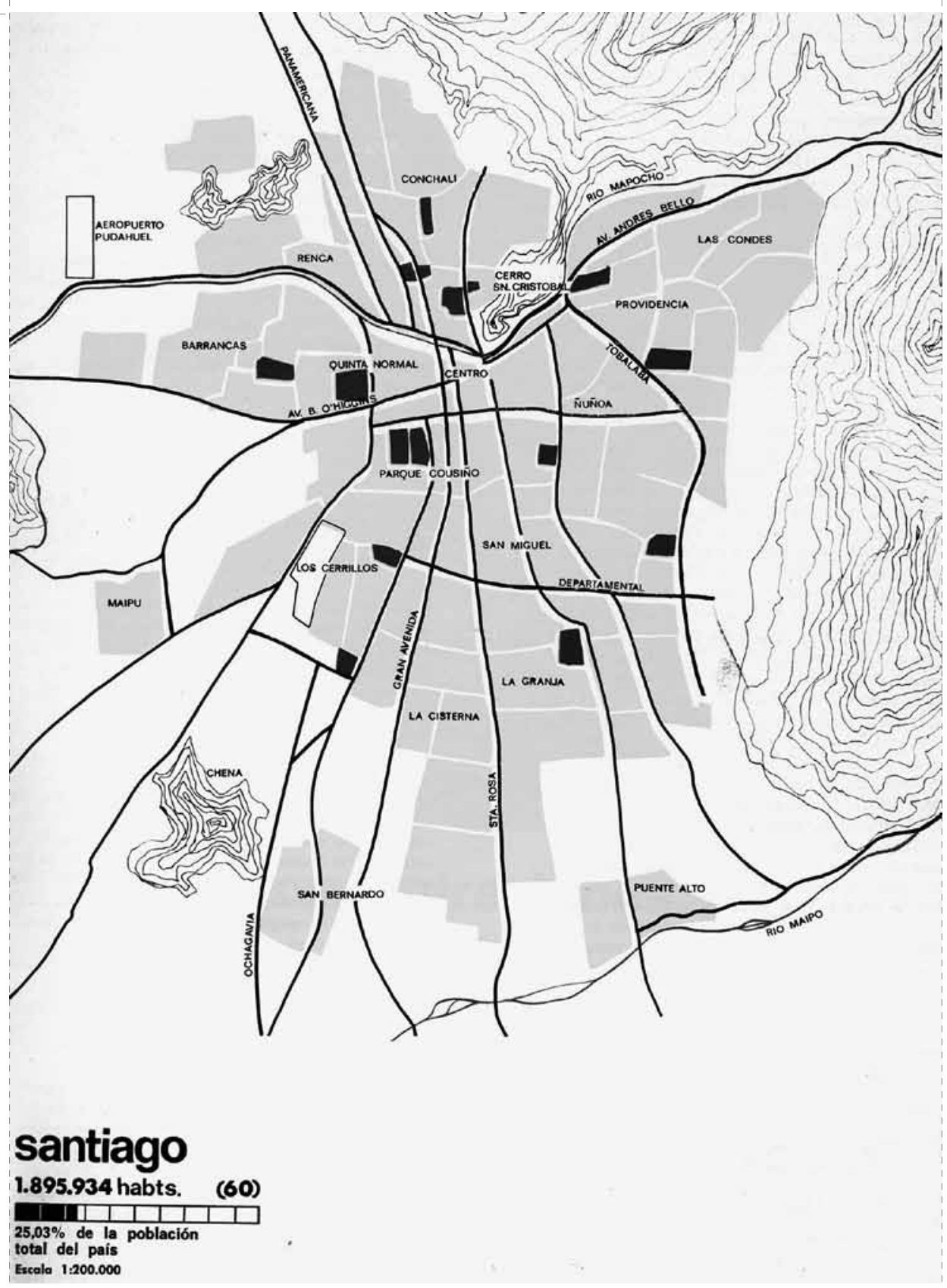

Crecimiento de Santiago, Censo de 1960 (Fuente: AUCA 1970; 17: p. 60)

de la crítica apuntó a la esquematización de la estructura urbana al reducir las actividades del individuo y de la sociedad a sólo cuatro funciones. La crítica, sin embargo, no iba tanto contra la validez de esta doctrina en su sentido general, sino a su incapacidad de adaptación al medio, en particular al latinoamericano y por extensión al chileno. El reconocimiento de nuevos valores sociales y culturales entró en oposición al esquema reduccionista de los
CIAM. La existencia de un tejido multicolor de funciones y subfunciones entrelazadas mostró una nueva perspectiva sobre el hecho urbano. La cuestión se centraba en considerar relaciones funcionales al interior de sectores integralmente planificados. En consecuencia, las actividades que conformaban la vida urbana debían situarse en cercanías relativas para crear relaciones locales ${ }^{14}$.

Francisco Vodanovic. Op. cit.; p. 40.

Facultad de Arquitectura, Universidad de Chile. La vivienda en el campo del planeamiento. ¿Dónde hacerla? X Congreso Panamericano de Arquitectos, Buenos Aires, 1960. Buenos Aires: Talleres Gráficos Optimus SRL, 1962; p. 189

Ibídem, pp. 189 y 190 
Calles de Santiago (Fuente: AUCA 1967, 10: p, 63)

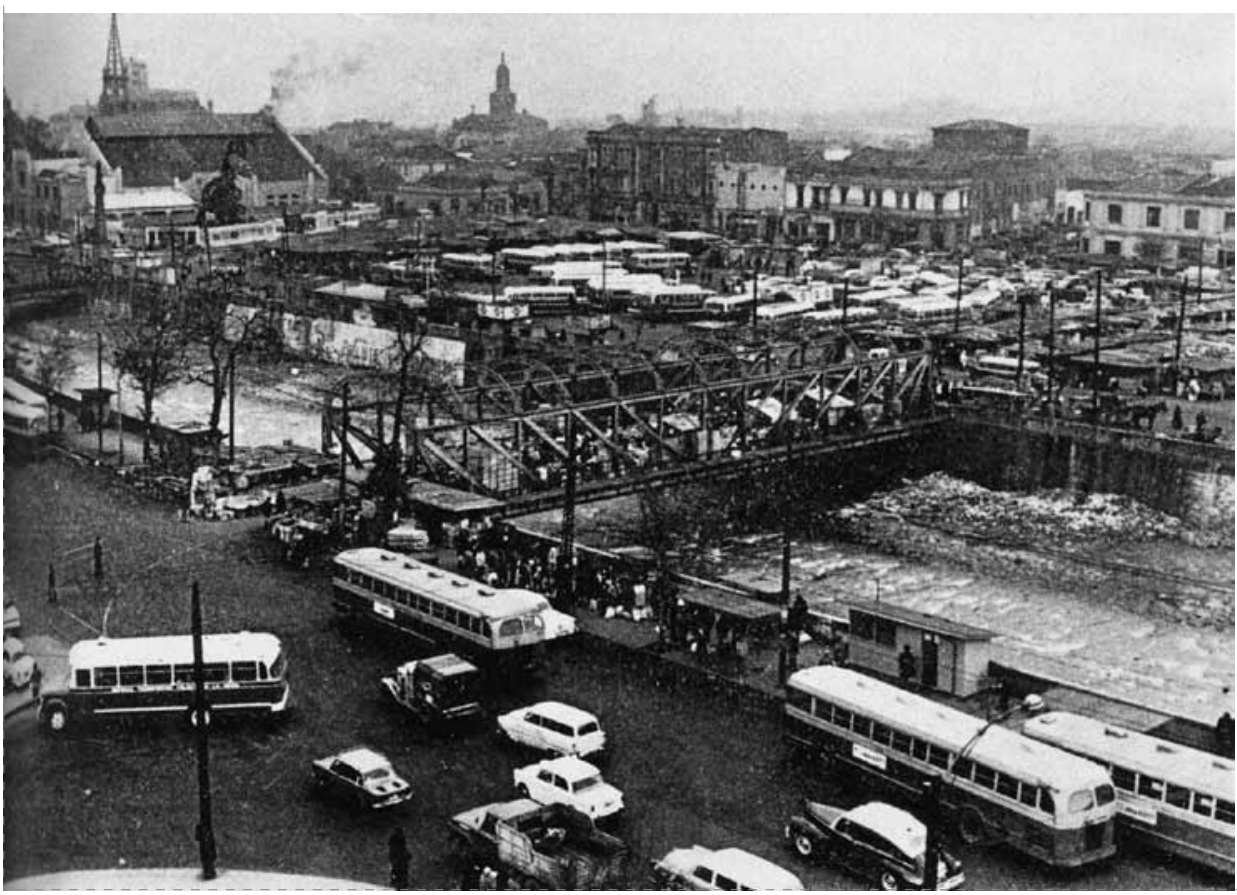

Por otra parte, la posibilidad de que los planes reguladores ejercieran cambios en beneficio de la ciudad en el corto plazo fue muy reducida. La escasa capacidad de operación y gestión de los instrumentos de planificación vigentes no había logrado contener la propagación del caos y la descomposición urbana. El sentimiento de que la estructura urbana de la ciudad estaba agotada a fines de los 60 pasó a ser una constatación. Santiago, la capital, fue el paradigma de este conflicto.

«Santiago sobrepasó, hace tiempo, los 2 millones de habitantes. El fenómeno de crecimiento de nuestra capital, más allá de las posibilidades inmediatas que ofrece su equipamiento, pone de manifiesto -en forma aguda- la falta de un enfoque nuevo, de una política diferente que cubra las problemáticas del desarrollo urbano» ${ }^{15}$

El desencanto social sobre la ciudad era producto de una contradicción urbana fundamental. Si en Chile el elevado proceso migratorio había demostrado que ser modernos implicaba habitar y ocupar la ciudad como una aspiración esencial de urbanidad, ¿cómo es que la ciudad se deterioraba por esa acción tan propia de la modernidad?
«La expansión demográfica y los fenómenos de densidad nos conducen a encrucijadas desconocidas, y así el valor de los terrenos muestran los primeros signos de estas precipitaciones; las especulaciones se desencadenan haciendo crecer las aglomeraciones artificialmente. El hombre de que construye y, sin embargo, acude cada vez más y en mayor número a él, pues la ciudad lo atrae irresistiblemente a pesar de todos sus problemas» ${ }^{16}$

En consecuencia, la extensión descontrolada de la ciudad, un fenómeno más plausible que el nacimiento de ciudades nuevas, cargaba con su propio designio en torno a su inminente aniquilación. Del mismo modo, el hacinamiento urbano, la mezcla desarticulada de funciones, la obsolescencia de sus sistemas de conexión, la descomposición espacial producida al interior de la estructura histórica de la ciudad, entre otros, desencadenó una concepción angustiosa de la ciudad

«La falta de actualización racional y permanente del Plan Regulador concluye en la plena vigencia de las normas arcaicas hoy es víctima de una inadaptación del mundo
Santiago, el fenómeno de la aglomeración (Fuente: AUCA 1970: 17: p. 82).

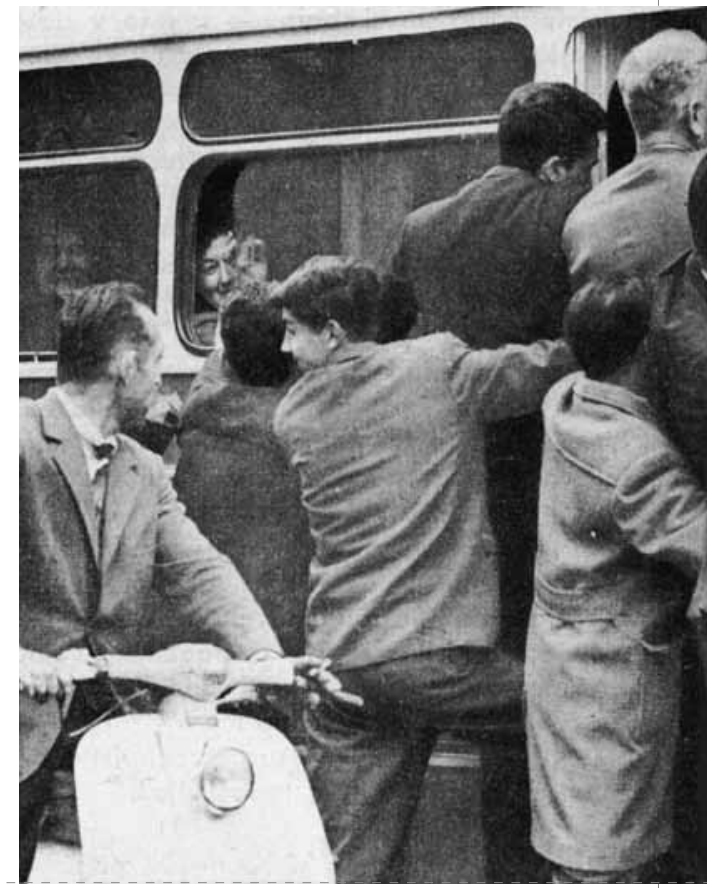

que inspiran nuestra Ordenanza Local y que imponen básicamente la edificación continua, de altura homogénea, en la misma división predial existente. En otras palabras mantiene la estructura de la calle corredor; impide la incorporación de las áreas libres al espacio urbano; conduce a la proliferación de patios de luz antihigiénicos; provoca deficiente aireación y asoleamiento de los recintos; reduce las áreas de circulación peatonal a estrechas veredas inmediatas a las vías de circulación de vehículos» ${ }^{17}$

EI XII Congreso Panamericano de Arquitectos (Bogotá, 1968), que tuvo por tema la «renovación urbana» constató que el hecho estaba generalizado por Latinoamérica. Las proyecciones continentales eran pocos auspiciosas. La vida urbana había llegado a un límite insostenible.

«(...) la vida en la ciudad se hace difícil, asfixiante, incómoda y exige una actitud técnica racional, que permita al hombre desarrollarse en paz, crecer armónicamente, dentro de formas urbanas que le aseguren su convivencia comunitaria» 18

5 CA. Chile: Editorial Desafío, 1968: 2

16 Jorge Gómez R. Santiago frente a algunos problemas de las ciudades contemporáneas. CA 1969. p. 13

Concurso Ministerio del Trabajo y Caja de EE.PP. AUCA No 10, p. 76

18 Eugenio Cienfuegos. Encuesta CA. CA 1968; 2: p. 19. 
Portada Revista AUCA, N 17, 1970

A dónde van nuestras ciudades?

(Fuente: AUCA 1970; 17).

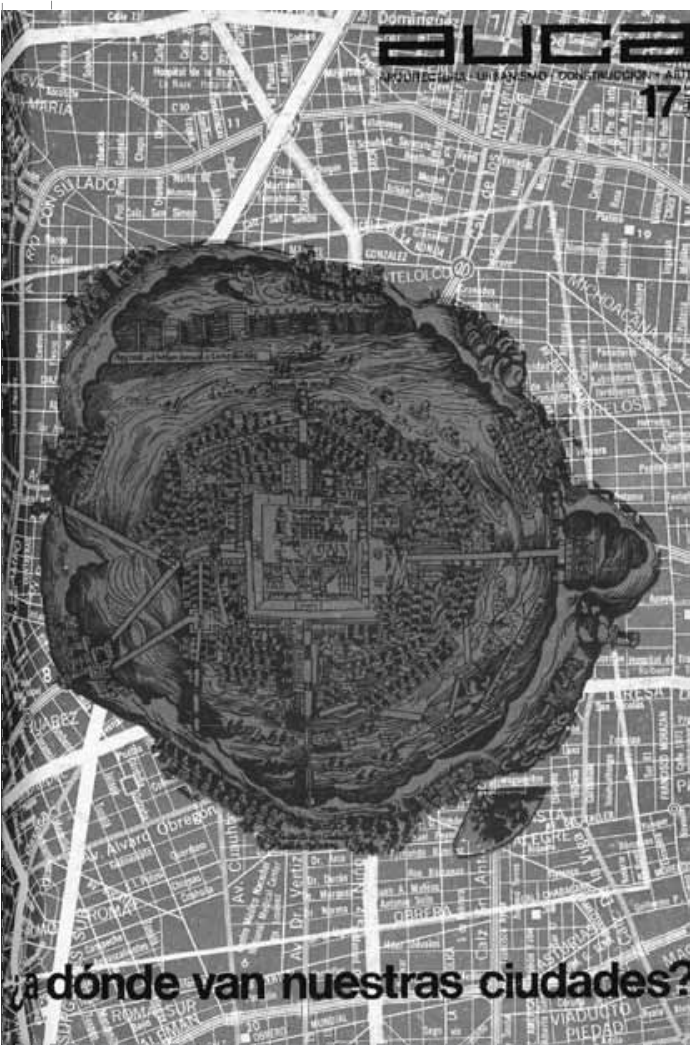

La ciudad, para finales de los años sesenta se convirtió en la imagen del cambio que el urbanismo tradicional había experimentado una vez que los acontecimientos

contemporáneos habían incidido sobre su desarrollo. Si por una parte, las aspiraciones de la teoría funcionalista moderna había tenido algunos ejemplos en la ciudad, las vicisitudes del progreso y sus numerosas incidencias desprogramadas habían terminado por cristalizar una confrontación entre la ciudad tradicional y la ciudad moderna. Para entonces, la falta de coincidencia entre forma, cultura y sociedad se reveló como una tensión inevitable. A nivel perceptual el cambio de escala, la sobredimensión, la ineficacia funcional, la falta de armonía del paisaje construido, etc., revelaron una crisis que se asentaba en las necesidades insatisfechas de la sociedad y en la falta de programación institucional.

«Hoy todo ha cambiado comenzando por la escala Ya no existe una sola función urbana dentro de un espacio único, sino una cantidad de funciones urbanas diferentes con espacios urbanos distintos. Literalmente la ciudad ha reventado; el gigantismo se ha apoderado de ella y los barrios se han extendido sin freno ni orden, provocando un despilfarro de tiempos

Santiago, la extensión urbana central (Fuente: AUCA 1970; 17: P. 58)

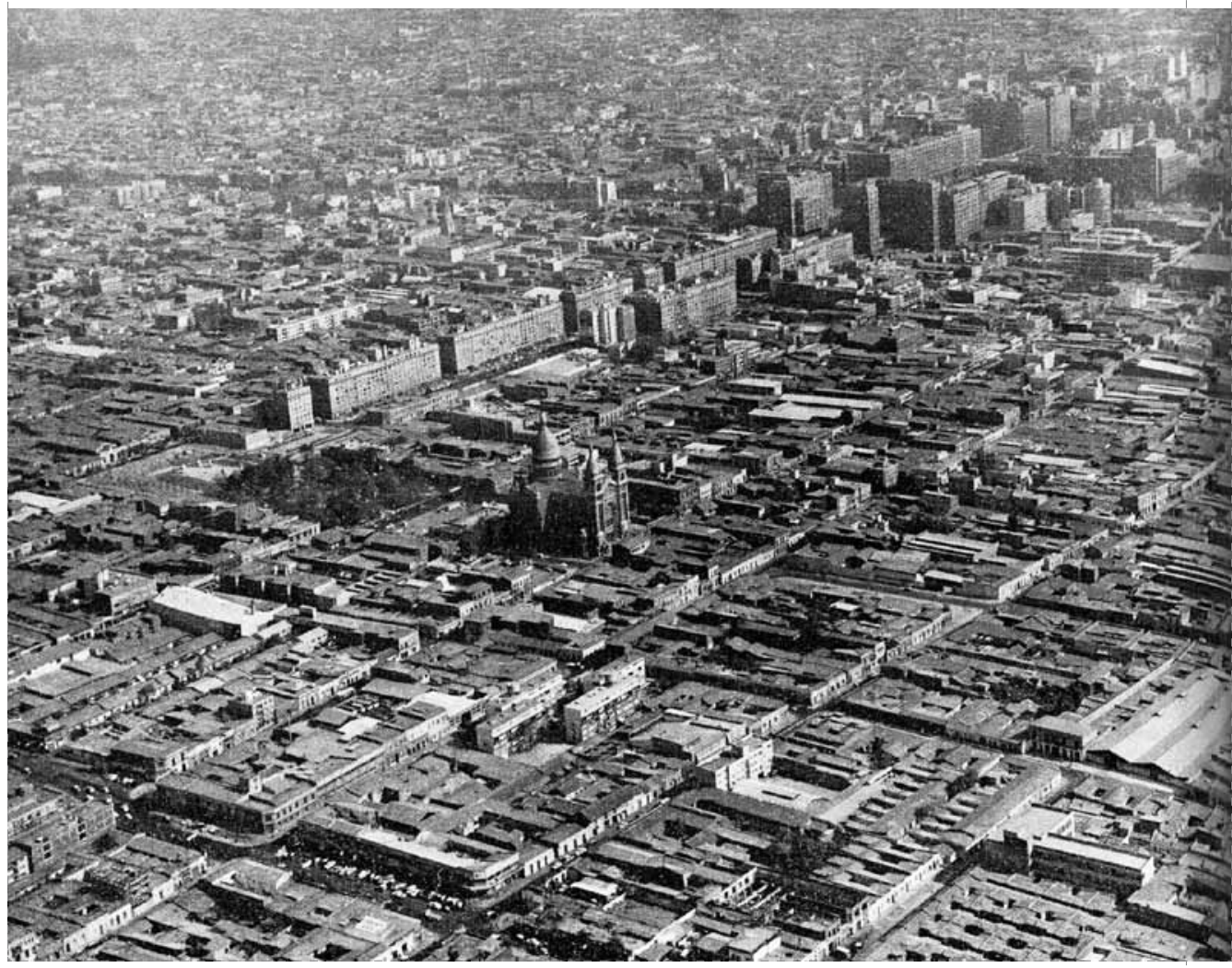

perdidos en desplazamientos y energías gastadas inútilmente, así como miles de metros cuadrados de suelo sacrificados... en aras de improvisación, desorden, crecimiento. El aumento de las necesidades del hombre, siendo la más visible el automóvil, ponen las ciudades en crisis; la consecuente inadaptación de la infraestructura urbana gravita cada día más sobre sus habitantes en desmedro de la libertad del individuo así como del presupuesto nacional sacrificado por el mal planteamiento y organización de las aglomeraciones» ${ }^{19}$.

Para entonces, en Chile se esgrimieron dos alternativas interactuantes: la necesidad de un plan de desarrollo y la colaboración activa de la comunidad organizada. En esas circunstancias, se trataba de extender la idea de que el cuidado y la solución de la ciudad no era cuestión del urbanista, sino de la complementariedad entre el conjunto de la comunidad y el Estado.

\footnotetext{
19 Jorge Gómez R. Op. cit.; pp. 12 y 13 René Martínez. Encuesta CA. CA 1968; 2: p. 23.
}

Sin embargo, en Chile, esta forma de solución se encontró con un escollo fundamental: la segregación social urbana. La ocupación disgregada del suelo por grupos sociales distintos hacía patente que en la ciudad las oportunidades de la modernidad estaban cercanas a unos y distantes de otros. Para René Martínez el sólo hecho de discuti sobre renovación urbana en un mundo subdesarrollado revelaba la brecha creciente entre el campo económico, tecnológico y social.

«Pero, querámoslo o no, ningún escamoteo podrá impedir que para nosotros, nacionales de cada uno de estos países que celebran congresos panamericanos para hablar de «renovación urbana», exista la pesadilla del desequilibrio ambiental, social y moral que convierte a nuestras ciudades en un mundo segregacionista e injusto, en el que solamente el egoísmo usado como coraza permite mantener una cierta, incierta y relativa tranquilidad de espíritu» ${ }^{20}$ 


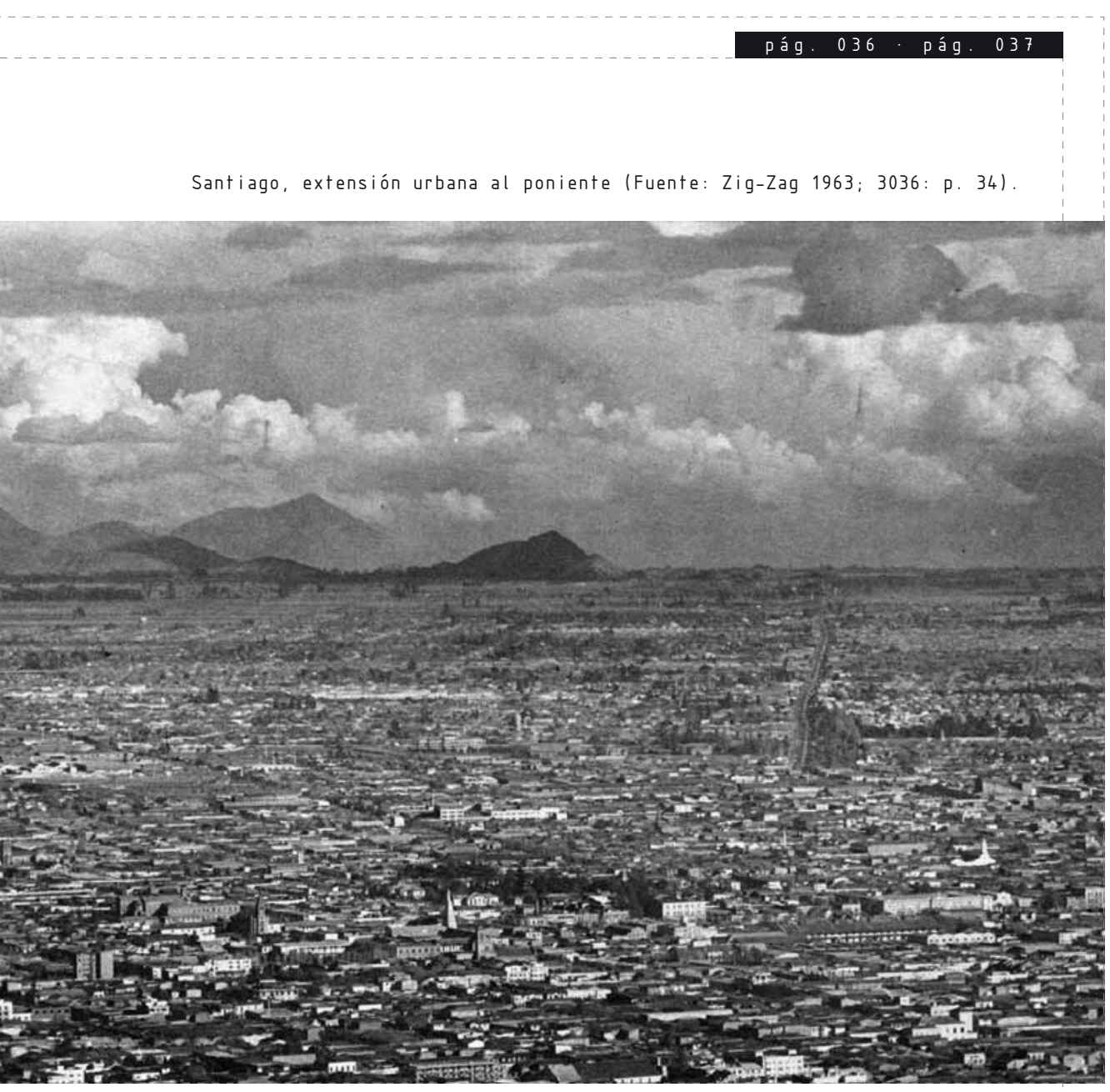

Efectivamente, Santiago se había transformado, como dice Martínez, en una desentonada agrupación de varias ciudades. Al oriente, los barrios Vitacura, Las Condes, Providencia y Ñuñoa, concentraban la riqueza, el prestigio social y el orden urbano. Su superficie ocupaba un quinto del total de la ciudad. Los cuatro quintos restantes permanecían en un proceso de deterioro paulatino «donde no hay lugar para sentimentalismos baratos de 'preservación' de un pasado cultural y arquitectónico de por sí bastante magro $(\ldots.) \otimes^{21}$

El quebrantamiento social de la ciudad fue consecuente con el deterioro de sus espacios urbanos. En 1968 Yolanda Schwartz acusó la pérdida de la escala en los espacios abiertos, la monotonía de sus perspectivas, la falta de unidad plástica en la composición volumétrica, la pobreza del diseño, el anacronismo del alhajamiento urbano y los «amaneramientos extraños al paisaje o a la idiosincrasia». Esta correspondencia entre el escenario y el drama social urbano fue la expresión de una sociedad cuya escala de valores había desplazado su interés desde el hombre como entidad social a grupos restringidos y privilegiados.

«(...) nuevamente la ciudad y su carácter de clase, Norte, Sur, Oriente, Poniente, son expresiones inequívocas de toda la gama social que divide a dos millones de habitantes. Basta un análisis de color. El blanco de estuco limpio, rojo de ladrillo, madera o teja, materiales nítidos y sobre todo el verde, verde en las avenidas, verde en los jardines, verde íntimo en que nada la arquitectura, dominan el Oriente. Negro de humo y fonolita, ocre gris de tierra, ocre gris de adobe, ocre gris de calles y avenidas. Ocre gris y negro, verde apenas, volúmenes chatos flotando en la tierra, dominan la periferia de Santiago, y también la atmósfera, el aire se tiñe, ya no es transparente» 22

A la postre, en términos urbanos, la tensión interior del trinomio hombre-ciudad-historia pasó a caracterizar la época. A modo de conclusión, se puede afirmar que la participación de la sociedad en todos los ámbitos se tornó una actividad relevante con capacidad de reconducir el debate. Se trataba de un momento en que la sociedad se sintió llamada a denunciar sus carencias y a participar de sus soluciones. Fue el momento de la denuncia de una crisis generalizada que ocupaba lugar en todas las discusiones. En lo general, el aumento descontrolado de la ciudad, el crecimiento demográfico, la segregación social-urbana, etc., fueron motivos suficientes para extender un descontento generalizado. En lo específico, el agotamiento de los recursos formales, la magnitud del déficit de vivienda, la incapacidad de Estado por dar solución a la mayoría de las necesidades urbanísticas y arquitectónicas nacionales se mostraban como las debilidades más relevantes. Se trata de factores que aparecían impulsando un proceso de crisis que abarcó no sólo el cuestionamiento de la vida social, sino de las mismas soluciones de la arquitectura.

\footnotetext{
21 Ibídem, p. 23

22 Yolanda Schwartz. Urbanorama. AUCA 1968; 13; p. 82.
} 